\title{
Incidence and determinants of newborn mortality in the first three days of delivery in Northwestern Ethiopia: a prospective cohort study
}

Mulugeta Dile Worke ( $\sim$ muliedile@gmail.com )

Debre Tabor University https://orcid.org/0000-0003-2540-9809

Afework Tadele Mekonnen

Jimma University College of Health Scinces

Simachew Kassa Limenih

Bahir Dar University College of Medical and Health Sciences

\section{Research}

Keywords: Neonatal death, obstructed labor, Amhara region, Ethiopia

Posted Date: August 17th, 2020

DOI: https://doi.org/10.21203/rs.3.rs-58092/v1

License: (c) (i) This work is licensed under a Creative Commons Attribution 4.0 International License.

Read Full License 


\section{Abstract}

Background: Addressing, the target of sustainable development goals of reducing perinatal mortality, was still a global challenge, and the magnitude of newborn death in the first three days of life takes a significant role in Ethiopia. Therefore, this study planned to determine the incidence and determinants of neonatal mortality in the first three days among babies delivered in referral hospitals of Amhara Regional State, North-Western Ethiopia.

Method: A hospital-based prospective cohort study design was conducted among 810 early neonates in the first three days of delivery between March 1 and August 30, 2018. The neonates were followed, starting from the time of admission to 72 hours. An interviewer-administered questionnaire and medical record review were conducted for data collection. Data were entered into Epi-data manager version 4.4 and analyzed using STATA ${ }^{\mathrm{TM}}$ version 16.0 for the analysis. Cox-Proportional hazard model was used to determine the survival time of the newborns.

Results: The overall incidence of newborn mortality in this study was $151 / 1,000$ births. Neonatal mortality was significantly high among newborns whose mothers came between 17 and 28 weeks of gestation for the first visit [AHR=1.67;95\% Cl: 1.02, 2.73], among those whose mothers labor was not monitored with a partograph [AHR=2.66; $95 \% \mathrm{Cl}: 1.70,4.15]$, mothers experience postpartum hemorrhage [AHR 2.88; 95\% Cl: 1.69, 4.89], develop fistula in the first 24 hours [AHR=3.75; 95\% $\mathrm{Cl}: 1.23,11.43$ ], and experience obstructed labor [AHR=2.14; 95\% Cl: 1.35, 3.38]. However, it was 39\% less risky among newborns whose mothers were directly admitted, and whose mothers had visited health facilities in less than 1-hour, both [AHR=0.61; 95\% Cl: $0.38,0.97]$.

Conclusion: This study revealed that about 1 in 7 newborns died in the early three days of life. The timing of the first antenatal visit, quality of labor monitoring, maternal complications, and delay in seeking the care were found to be the determinants. Thus, scaling-up of evidence-based interventions, and harmonized efforts aimed to improve the quality of antenatal care, promote institutional deliveries, provide optimal essential and emergency obstetric care, and ensure immediate postnatal care may improve neonatal survival.

\section{Background}

The newborn period is critical in the miracle of life and death. However, in 2018, the global neonatal mortality rate was estimated at 18 deaths per 1,000 live births [1]. There were 28 deaths per 1,000 live births in Sub-Saharan Africa [1] and 30/1000 live births in Ethiopia [2]. According to a systematic review in developing countries, $57 \%$ of neonates die in the first three days of life, and two-thirds of these deaths occur within the first 24 hours[3]. This study also indicated that among $52 \%$ of under-five mortality in the Southeast Asia region, one-third of the neonatal mortality occurred within the first three days of life, and among $30 \%$ of the under-five deaths in the World Health Organization (WHO) African region, $17 \%$ of the deaths occur within the first day of life [3]. WHO also confirms that the death risk is the peak in the first 24 
hours of life, and more than half of deaths and about three-quarters of all neonatal deaths occurred within the first week of life [4]. In Ethiopia, a study revealed that the death of babies who came between the age of $1-3$ days was riskier than $4-7$ days [5].

It has been suggested that the scaling-up of evidence-based interventions that begin at the antenatal period, coordinated efforts aimed at improving the quality of antenatal care, promoting institutional deliveries, providing optimal essential and emergency obstetric care, and ensuring immediate postnatal of neonates are essential in low and middle-income countries $[3,6]$. Some countries, including Ethiopia, have made substantial progress in achieving targeted coverage for some interventions. However, these coverages have not resulted in the expected magnitude of reduction in neonatal mortality rate, specifically neonatal mortality within the first three days of life. The possible reasons were the provision of suboptimal quality of care in health facilities, and lack of concomitant increase in the coverage of the critical interventions in the continuum of care [3]. For example, a recent study in Ethiopia indicated that only $12.1 \%$ of women completed the continuum of maternal care services, and $25.1 \%$ of them did not receive any care during their recent births [7].

Previous work identified multiple risk factors of neonatal mortality [8-12]. Among them, poverty is an underlying cause of many neonatal deaths either by increasing the prevalence of risk factors such as maternal infection or through reducing access to adequate care [13]. Studies also revealed that the proportions of common causes of neonatal mortality as prematurity account for $17 \%$; asphyxia for $25 \%$; $37 \%$ was due to infection; tetanus $7 \%$; diarrhea $3 \%$; congenital malformations $4 \%$; and $7 \%$ were other causes [14-17]. However, almost all the studies were conducted either at the community level or within 28 days of life. Furthermore, there is a paucity of evidence in the first three days of life and at the tertiary hospital level. Therefore, understanding the distribution of the risk factors for early neonatal death is essential for arranging programs and identifying suitable interventions. There should be local and recent evidence about the spread of the problem and apply reason types that are programmatically relevant for decision-making [8]. Moreover, since both biology and empirical data suggest that the cause of death distribution differs substantially between these periods, separate cause-of-death estimates are required for the first three days of life, within the first seven days, and within 28 days of life [8].

However, a significant number of newborns are dead in tertiary care hospitals. However, the incidence and determinants of neonatal mortality within the first three days of life in tertiary care hospitals are limited. Therefore, this study aimed to address the incidence and determinants of newborn death in the first three days among babies delivered in referral hospitals, which will help in designing the appropriate interferences that might be applied to advance their survival.

\section{Methods}

\section{Study setting and period}

This study was conducted at the maternity wards of referral hospitals in Amhara Regional State between March 1 and August 30, 2018. The National Regional State is located between $9^{\circ} 20 \otimes$ and $14^{\circ} 20 \otimes$ North 
latitude and $36^{\circ} 20 \otimes$ and $40^{\circ} 20 \otimes$ East longitude in the Northwestern part of Ethiopia. According to the Central Statistics Agency, the projected total population estimate Amhara Region the year 2020/21, is estimated to be $22,536,999$ (11, 236, 853 males, $11,300,146$ females). Of which $20.08 \%$ were urban residents [18].

As per the annual performance report published by the Federal Ministry of Health (MOH) of Ethiopia in the 2009 Fiscal Year, Amhara National regional state has about 68 hospitals, 841 health centers, and 3342 health posts [19]. At the time of data collection for this study, among the 68 functional hospitals in the region, Dessie, Felege-Hiwot, University of Gondar, Debre-Birhan, and Debre-Markos were referral hospitals. Thus, all five referral hospitals serve the population found in the region. Each referral hospital is assumed to render services for 5 million people, have100-200 beds, 2000-3000 deliveries per year, and 5-8 deliveries per day. According to the annual registration of each hospital in 2019 , each referral hospital served approximately 4500 mothers per year on average.

The three selected referral hospitals were the University of Gondar Teaching Referral Hospital, Felege Hiwot Referral Hospital, and Debre Markos Referral Hospital. The University of Gondar Hospital is one of the oldest academic institutions in Ethiopia. It has produced several health professionals for more than half a century ago. This University is located at the heart of Gondar city, found in the Amhara Region, in the northwestern part of Ethiopia. Gondar city is also located $727 \mathrm{~km}$ away from Addis Ababa (the capital city of Ethiopia). This hospital offers different inpatient and outpatient services to the population in the surrounding area of Gondar town and the nearby zones. The Felege-Hiwot referral hospital is also one of the largest Hospitals situated in the capital city of the regional state, which is located $578 \mathrm{~km}$ away from the capital of Ethiopia, Addis Ababa, in the North West direction. It obliges as a referral hospital for the population around the Bahir Dar exclusive zone, west Gojjam zone, Awi zone, and South Gondar Zone, which are the residences of more than 7 million people. It is also serving as a teaching hospital for the Bahir Dar University. Similarly, Debremarkos referral hospital is located $295 \mathrm{~km}$ from Addis Ababa, the capital of Ethiopia and $265 \mathrm{~km}$ from Bahirdar, the capital city of Amhara regional state. This hospital is likely to provide services for more than 3.5 million people in its catchment area. Apart from other services, the hospital provides ANC and delivery services for pregnant women.

\section{Study design and population}

An institution-based prospective cohort study was conducted among a cohort of term pregnant mothers, and newborns admitted to three systematically selected referral hospitals. All term pregnant mothers ( $\geq$ 37 weeks gestational age (GA)) were admitted to the selected referral hospitals that were included in this study. Then, followed up until they gave birth, and their neonates were followed up for a total of 72 hours. Cohorts of newborns who were delivered from women aged 15-49 years were included. On the other hand, those who were delivered from women with mental illness and unable to hear and talk due to illness, and twins were excluded from the study.

\section{Sample size and sampling technique}


The sample size of 832 was calculated using Epi-info version 7 stat calc software. The following assumptions of the incidence ratio of early neonatal death of 369 per 2142 deliveries [20], 95\% confidence level, the margin of error 2.75 , and $15 \%$ lost to follow-up.

Systematic random sampling was used to identify 810 admitted term pregnant women to be enrolled in the follow-up study. First, a simple random sampling (i.e., lottery method) technique was employed to select the three hospitals out of the five (i.e., Felege Hiwot referral hospital, Debre Markos referral hospital, and University of Gondar referral hospital). Then, the study subjects were allocated with the proportion of the expected number of admissions of term pregnant women per referral hospital. Then, the calculated sample was selected consecutively from each referral hospital.

\section{Variables}

Times-to-event, the event of interest was early neonatal death and dichotomized as (alive $=1$ and died = 0 ). The determinant variables included socio-demographic and economic factors: ethnicity, religion, place of residence, marital status, education status of the mother, and occupational status of the mother, age of mother, maternal and neonatal related factors: ANC follow up, parity gravidity, mode of delivery gestational age, birth weight, age of neonate at discharge, and sex of neonate. Neonatal illnesses include respiratory distress, perinatal asphyxia, sepsis, congenital malformation, hyaline membrane disease, and meconium aspiration syndrome. Care/ service-related factors: Partograph follow-up, length of stay, and obstetric complications.

\section{Operational definition}

Early neonatal mortality: This refers to the death of a neonate within the first 72 hours of life.

Neonatal survival: is referred to as being alive up to the end of the follow-up period (72 hours).

Term pregnancy is a pregnancy between 37 completed weeks up to 42 completed weeks of gestation.

\section{Data quality assurance and tools}

The questionnaire was primarily ready in English, translated to the local language Amharic, and back to English by different individuals to check its consistency. The survey was pretested on 42 mothers (14 exposed and 28 unexposed cohorts) in Debre Tabor Hospital, which differs from the study hospitals. The questionnaire (S1 Appendix 1 and 2) was then assessed for its clarity and completeness. Some skip patterns were corrected, and questions difficult to ask were rephrased. The questionnaire had three parts. The first part was socio-demographic factors (i.e., maternal age, body mass index, age at first marriage, age at early pregnancy, age at first delivery, ethnicity, residence, marital status, educational status, husband educational status, occupation, an estimated distance of home from health institution, determining range from primary health institute to tertiary center, religion, and income). The second part was reproductive factors like gravidity, parity, gestational age, referral status, birth attendant, previous cesarean section, mode of last delivery, antenatal care attendance, number of ANC visits, duration of labor before the presentation, prior history of abortion and obstetric complications. The third part was 
that programmatic factors included infrastructure and transportations. The completed questionnaires were checked day-to-day for inclusiveness, correctness, clarity, and consistency by the supervisors, and the principal investigators and necessary corrections and changes were made. Completeness and consistency of variables during data entry and analysis were checked using frequency distributions, cross-tabulations, sorting in ascending, and descending order.

\section{Data collection process}

Six bachelors (two per hospital) holders experienced midwives collected data, and three general practitioners were recruited for supervision. Three days of training given, focusing on the objective of the study and the value of collecting the actual data. The structured questionnaire was discussed in detail, going through every question, and clarification was provided. A field manual was prepared for the supervisors and data collectors for use during data collection. The six data collectors were present in the respective hospitals during the complete 24 hours.

The data collectors collected the data daily. An interviewer-administered questionnaire and medical record review were used to collect data on the intended variables of interest until the time of discharge from the hospital or 72 hours. In cases in which readmission occurred, only the previously collected data were retained for analysis. The neonates were assessed for the entire period of hospital stay (both in the maternity ward and neonatal intensive care unit). There was no follow-up after hospital discharge.

\section{Data management and analysis}

Early neonatal mortality was the event of interest, which was coded as " 1 " for failure and " 0 " for censored. Time-to-event was considered by subtracting the date of admission from the time of the event. Data entered into Epi-Data manager version 4.4 and analyzed using STATA ${ }^{\text {TM }}$ version 16.0. The mean and standard deviation were calculated for the follow-up time and age of the cohort. The cox-Proportional hazard model was used to determine risk factors for the survival time of newborns delivered at the hospitals. A tolerance level with a cut point of 0.2 was used to omit multicollinearity.

The Kaplan Meier curves were used to estimate survival time. The log-rank test was used to look at statistical variances between the groups of variables. Statistical significance was declared at p-value < 0.05. A summary statistic of proportions, including hazard ratio and $95 \%$ confidence intervals as used. Screening of risk factors for the newborn's death was done employing bivariate Cox regression for each variable one at a period. Then, those variables with $p<0.25$ throughout the bivariate Cox regression analysis were taken as an entrant variable for the multivariate Cox regression model to control possible confounders.

\section{Results}

During the 72 hours' observation, 810 newborns ( $97.4 \%$ of the sample) followed for 37,454 new-bornshours at the three hospitals. The mean ( \pm SD) length of stay at the four hospitals was $46.23( \pm 29.31)$ hours. Of the 810 newborns, $10.12 \%$ were stillbirths, $17.04 \%$ were alive but complicated, and $72.59 \%$ were alive without complications. 


\section{Newborn and maternal characteristics}

Four hundred ninety-nine (61.6\%) of the women in the study resided in an urban area. Of the 810 mothers, $95.31 \%$ of them were married. The mean age of the women was $27.66( \pm 5.55)$; the majority $(40 \%)$ were aged $26-30$ years. As Table 1 shows, $30.12 \%$ of the mothers were unable to read and write by educational status, and $17.28 \%$ were grand multiparous.

Table 1

New-borns and maternal characteristics of Amhara regional state referral hospitals, Northern Ethiopia, 2018.

\begin{tabular}{|c|c|c|c|}
\hline Variables & Categories & Frequency & Percent \\
\hline \multirow[t]{2}{*}{ Residence } & Urban & 499 & 61.6 \\
\hline & Rural & 311 & 38.4 \\
\hline \multirow[t]{5}{*}{ Maternal age group } & Less than 21 years & 11.60 & 11.60 \\
\hline & 21 to 25 years & 208 & 25.68 \\
\hline & 26 to 30 years & 324 & 40.00 \\
\hline & 31 to 35 years & 105 & 12.96 \\
\hline & Greater than 35 years & 79 & 9.75 \\
\hline \multirow[t]{2}{*}{ Marital status of mothers } & Married & 772 & 95.31 \\
\hline & Single & 38 & 4.69 \\
\hline \multirow[t]{5}{*}{ Educational level mother } & Unable to read and write & 244 & 30.12 \\
\hline & Able to Read and write & 124 & 15.31 \\
\hline & Primary education & 107 & 13.21 \\
\hline & Secondary Education & 134 & 16.54 \\
\hline & More than secondary & 201 & 24.81 \\
\hline \multirow[t]{3}{*}{ Mothers monthly income } & $\leq 1500$ ETB & 362 & 44.69 \\
\hline & 1501 to 3000 ETB & 274 & 33.83 \\
\hline & $\geq 3001$ ETB & 174 & 21.48 \\
\hline \multirow[t]{3}{*}{ Parity } & Primipara & 330 & 40.74 \\
\hline & 2 to 4 children & 340 & 41.98 \\
\hline & 5 children and above & 140 & 17.28 \\
\hline \multirow[t]{2}{*}{ sex of the baby } & Female & 377 & 46.54 \\
\hline & Male & 433 & 53.46 \\
\hline
\end{tabular}


Table 2

survival function life table of Amhara regional state referral hospitals, Northern Ethiopia, 2018

\begin{tabular}{|lllllll|}
\hline Time & $\begin{array}{l}\text { Beg } \\
\text { Total }\end{array}$ & Fail & Net & Survivor Function & $\begin{array}{l}\text { Std } \\
\text { Lost }\end{array}$ & [95\% Conf. Int.] \\
\hline 1 & 810 & 82 & 0 & 0.8988 & 0.0106 & 0.87590 .9176 \\
\hline 6 & 728 & 0 & 117 & 0.8988 & 0.0106 & 0.87590 .9176 \\
\hline 12 & 611 & 0 & 2 & 0.8988 & 0.0106 & 0.87590 .9176 \\
\hline 20 & 609 & 1 & 1 & 0.8973 & 0.0107 & 0.87420 .9163 \\
\hline 24 & 607 & 15 & 95 & 0.8751 & 0.0119 & 0.84980 .8964 \\
\hline 48 & 497 & 6 & 68 & 0.8646 & 0.0125 & 0.83800 .8871 \\
\hline 50 & 423 & 1 & 0 & 0.8625 & 0.0126 & 0.83570 .8853 \\
\hline 52 & 422 & 1 & 0 & 0.8605 & 0.0127 & 0.83330 .8835 \\
\hline 72 & 421 & 16 & 405 & 0.8278 & 0.0146 & 0.79680 .8544 \\
\hline
\end{tabular}

\section{Neonatal illness}

The leading cause of disease in Amhara regional state referral hospitals was neonatal jaundice (42.4\%), followed by other complications (24.65\%) like birth trauma, congenital anomalies, and asphyxia (17.70\%) (Fig. 2).

Of the 688 newborns discharged, $56.69 \%$ were discharged alive, $2.47 \%$ were discharged with treatment, and $17.30 \%$ were referred to the neonatal intensive care unit (ICU). In contrast, the rest of the $23.55 \%$ were discharged with an appointment.

\section{Neonatal survival}

During the study period, a total of $15.06 \%(n=122)$ new-borns deaths were observed, making an overall newborn mortality rate of 151 per thousand births. Of the 122 newborn deaths, 82(67.21\%) were stillbirths (672.1/1000 births), 16(13.11\%) died in the first 24 hours (131.1/1000 births), and 24(19.67\%) (196.7/1000 births) died within 25 to 72 hours. The overall incidence of new-borns mortality was 3.25 per thousand early neonate-hours.

\section{Kaplan-Mair Survival Analysis}

There was a higher mortality level in the first 24 hours compared to after 24 to 72 hours. This finding indicates that there is a substantial reduction in death after the neonates survive the early 24 hours of life 
in the observation period (Fig. 3). Similarly, the curve indicates that neonatal mortality shows substantial decrement among those whose labor was monitored with Partograph (Fig. 4).

\section{Determinants of neonatal mortality}

We included the variables with a p-value of less than 0.25 in the crude model in the Cox proportional hazards regression model. Then, after controlling for potential confounders using multivariate Cox proportional hazard regression, the timing of first antenatal care visit, monitoring with partograph, type of admission of the women, and maternal complications within the first 24 hours (postpartum hemorrhage, fistula, and obstructed labor) were the variables that determine neonatal survival within the first 72 hours of life.

Gestational age at the first antenatal care visit was found to be a risk factor for newborn mortality. Women who came between 17 and 28 weeks of gestation for the first visit were 1.67 times more likely to lose their child [AHR $=1.67: 95 \% \mathrm{Cl}: 1.02,2.73]$ compared to those who started the initial antenatal care visit before 16 weeks of gestation. Mothers not monitored with a partograph during labor were 2.66 times the risk of newborn mortality $[\mathrm{AHR}=2.66: 95 \% \mathrm{Cl}$ : $1.70,4.15]$ compared to their counterparts. Direct admission was $39 \%$ less risk of neonatal death than [AHR $=0.61: 95 \% \mathrm{Cl}: 0.38,0.97$ ] those admitted from referral to another health facility.

Maternal complications within 24 hours were also a significant risk factor for newborn mortality. Mothers experiencing postpartum hemorrhage were about three times risky for new-borns death $[A H R=2.88 ; 95 \%$ Cl:1.69, 4.89], and those who developed fistula in the first 24 hours were also about four times risky for new-borns death $[A H R=3.75 ; 95 \% \mathrm{Cl}: 1.23,11.43]$. Obstructed labor was more than twice risky [AHR = 2.14; $95 \% \mathrm{Cl}: 1.35,3.38$ ] for new-borns mortality and less than 1 hour maternal first delay in visiting health facility was $39 \%$ less risk of new-borns death [AHR $=0.61 ; 95 \% \mathrm{Cl}: 0.37,0.98$ ] (Table 3 ). 
Table 3

Bivariate and Multivariate Cox-proportional hazard regression for the first three days neonatal mortality in Amhara regional state referral hospitals, Northern Ethiopia, 2018

\begin{tabular}{|c|c|c|c|c|}
\hline \multirow[t]{2}{*}{ Variables } & \multicolumn{2}{|l|}{ Outcome } & \multirow[t]{2}{*}{ CHR $(95 \% \mathrm{Cl})$} & \multirow[t]{2}{*}{ AHR (95\%Cl) } \\
\hline & Died & Censored & & \\
\hline \multicolumn{5}{|l|}{ Parity } \\
\hline 1 child & $38(4.69)$ & 292(36.05) & 1.0 & 1.0 \\
\hline 2-4 children & $48(5.93)$ & 292(36.05) & $1.26[.82,1.93]$ & $1.20[0.74,1.94]$ \\
\hline 5 children \& above & $36(4.44)$ & $(104) 12.84$ & $2.25[1.43,3.56]$ ** & $0.92[0.52,1.64]$ \\
\hline \multicolumn{5}{|c|}{ Gestational age for the first antenatal care visit } \\
\hline$\leq 16$ weeks & $34(4.42)$ & $343(44.55)$ & 1.0 & 1.0 \\
\hline 17 to 28 weeks & $62(8.05)$ & $307(39.87)$ & $1.84[1.21,2.80]$ * & $1.67[1.02,2.73]$ * \\
\hline$>28$ weeks & $10(1.30)$ & $14(1.82)$ & $4.49[2.22,9.10] \star \star$ & $1.21[0.51,2.84]$ \\
\hline \multicolumn{5}{|c|}{ Monitored with partograph } \\
\hline Yes & $63(7.78)$ & $598(73.83)$ & 1.0 & 1.0 \\
\hline No & $59(7.28)$ & $90(11.11)$ & $4.48[3.13,6.39] \star \star$ & $2.66[1.70,4.15]$ ** \\
\hline \multicolumn{5}{|c|}{ Maternal mode of admission } \\
\hline Direct admission & $44(5.43)$ & 437() & $.37[.25, .53] \star \star$ & $0.61[0.38,0.97]$ * \\
\hline Referral & $78(9.63)$ & 251(30.99) & 1.0 & 1.0 \\
\hline \multicolumn{5}{|c|}{ Mothers complications within 24 hours } \\
\hline Abdominal distension & $23(2.84)$ & $68(8.40)$ & $2.63[1.63,4.26]$ ** & $1.24[.67,2.32]$ \\
\hline $\mathrm{PPH}$ & $34(4.20)$ & $38(4.69)$ & $5.79[3.79,83]$ ** & $2.88[1.69,4.89]$ ** \\
\hline Fistula & $5(0.62)$ & $4(0.49)$ & $6.59[2.64,16.43]$ ** & $3.75[1.23,11.43]$ * \\
\hline No complication & $60(7.41)$ & $578(71.36)$ & 1.0 & 1.0 \\
\hline \multicolumn{5}{|l|}{ Obstructed Labor } \\
\hline Yes & $74(9.14)$ & 196(24.20) & 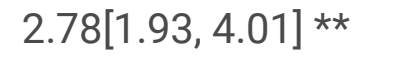 & $2.14[1.35,3.38]$ * \\
\hline No & $48(5.93)$ & 492(60.74) & 1.0 & 1.0 \\
\hline \multicolumn{5}{|l|}{ Maternal first Delay } \\
\hline$<1$ hour & $55(6.79)$ & $560(69.14)$ & $.25[.17, .36] \star \star$ & $0.61[0.37,0.98]$ * \\
\hline
\end{tabular}




\begin{tabular}{|c|c|c|c|c|}
\hline \multirow[t]{2}{*}{ Variables } & \multicolumn{2}{|l|}{ Outcome } & \multirow[t]{2}{*}{$\mathrm{CHR}(95 \% \mathrm{Cl})$} & \multirow[t]{2}{*}{ AHR $(95 \% \mathrm{Cl})$} \\
\hline & Died & Censored & & \\
\hline$\geq 1$ hour & $67(8.27)$ & $128(15.80)$ & & 1.0 \\
\hline
\end{tabular}

\section{Discussion}

Losing a newborn within the first three days of life, during which high neonatal mortality occurred, was shocking for the family, community at large and is devastating globally. Especially in developing countries, addressing this issue was difficult tasks for several factors.

In this study, out of 810 babies born at the referral hospitals of Amhara regional states, 122 neonates were lost their lives within the first three days of life, giving an overall newborn mortality rate of 151/1000 births. Similarly, the stillbirth rate was $672.1 / 100$ births. This figure shows a significant decline from a study conducted in the Black lion hospital (225/1000 live births) [21]. This decline might be due to the impacts of different interventions for the last six years across the country. However, it was much higher than the global neonatal mortality rate in 2016 [22], and in studies conducted in Southern Ethiopia [23, 24], Eastern Ethiopia [25], Southwest Ethiopia [26], Sudan [27], Uganda [20] and Zambia [28]. The variances might be attributed to study designs, health service coverage, and socioeconomic factors. This finding might also be because of the admission of complicated mothers in referral hospitals. This finding implies that the situation of neonatal mortality is still not progressing as anticipated in referral hospitals, and strengthen the argument made by the study conducted in Jimma Zone [26], and a previous systematic review [6], which concluded that "health facility delivery had no significant effect on neonatal mortality." However, the findings of this study should be interpreted vigilantly because the reports of stillbirth rate among admitted term pregnant women in referral hospitals, and possible misclassification of pregnancy outcomes (e.g., severe asphyxia of neonates) might overestimate the actual burden of stillbirth in the study area. Though there might be due to differences based on some factors, we suggest tailored and targeted interventions by all stakeholders at different levels.

Regarding the determinants of neonatal mortality within the first 72 hours, gestational age at the first antenatal care visit was found to be a risk factor. Women who came between 17 and 28 weeks of gestation for the first visit were 1.67 times more likely to lose their child as compared to those who started the initial antenatal care visit before 16 weeks of pregnancy. This finding is similar to studies conducted in Tigray regional state [29], Felege Hiwot referral hospital [30], and Gaza-Strip [31]. This result infers that the earlier the start of prenatal care visits, the more the mothers will have time to complete four follow-ups. This will, in turn, help us a new method of obstetric problems, which suggests the recent WHO recommendation of positive pregnancy experiences [32]. Thus, this study suggests the early start of the 
antenatal visit and possible consideration of the new WHO recommendation for antenatal care visits in Ethiopian referral hospitals.

Maternal complications within 24 hours were also a significant risk factor for newborn mortality. Of these, the experience of postpartum hemorrhage, development of fistula within the first 24 hours, and obstructed labor were found to be three times, four times, and more than twice risky for new-borns death within the first 72 hours of life. The finding of our study regarding fistula and postpartum hemorrhage as risks for neonatal mortality was unique in this finding. The possible reason for neonatal mortality among mothers facing postpartum hemorrhage and fistula might be intrapartum asphyxia. In cases of maternal complications, the attention of health care providers diverts to saving the mother, and in some cases, neonates would not get adequate care, which leads them to intrapartum asphyxia. However, future research should be conducted to get the exact cause of neonatal mortality in such complications. However, the results of this study, which identified obstructed labor as a risk of neonatal mortality, was similar to studies conducted in Hawassa University hospital, Ethiopia [33], and tertiary hospitals in Tanzania [34]. This is due to asphyxia and other related consequences of prolonged labor that leads to premature neonatal death.

Moreover, mothers who were not monitored with partograph during labor were nearly three times the risk of newborn mortality as compared to their counterparts. This result was supported by a study in Addis Ababa [35], and a study in Tigray regional state [29]. This outcome entails feto-maternal health should be monitored with the start of the active first stage of labor for timely management of prolonged labor, and its consequences will be early identified as prevention and control of early neonatal death.

Furthermore, direct admission was $39 \%$ less risk of newborn mortality than those admitted from referral to another health facility. In other words, mothers who require a referral were either suffer from severe obstetric problems or transfer time. We extend the time to receive skilled care. Besides, less than one hour of maternal first delay to visit health was $39 \%$ less risk of newborn death. This result was similar to a study in Tigray Northern Ethiopia, showing that seeking skilled care at the start of labor was protective for perinatal mortality [29]. This result indicates the first delay in the road to maternal death were also has a significant contribution in the early neonatal death. We suggest that health care providers should pay attention to the care for newborns with significant intrapartum asphyxia, including respiratory, temperature, and nutritional support.

This study has some inherent limitations. First, though this study was unique in addressing the first three days of life with a follow-up study design to determine the risk factors of early neonatal mortality, being only at the tertiary level of care may elevate the estimate of the actual incidence of premature neonatal death of the region. Second, the study was based on tertiary hospitals and may not show the picture of secondary and primary hospitals, and data were only collected up to 72 hours of the life of the newborns and, therefore, cases occurring after 72 hours were missed. Third, a mixed-method study design should have been used to identify the issues related to the perception of mothers and health care providers on the quality of services provided in the referral hospitals. Thus, Future research should be conducted to 
encompass the full 28-day postnatal period, mixed-method, and compare the neonatal mortality at the primary, secondary, and tertiary level of care.

\section{Conclusion}

About 1 in 7 newborns died in the first three days of life in the tertiary level of care in North-Western Ethiopia. The leading causes of newborn death were neonatal jaundice, followed by other complications, like birth trauma, congenital anomalies, and asphyxia.

Maternal risk factors for the newborn mortality such as women who came between 17 and 28 weeks of gestation for the first visit and more than 1-hour maternal first delay to visit a health facility, and health system-related risk factors such as mothers not monitored using partograph during labor, admission by referral from other health facility were the significant factors. Furthermore, obstetric risk factors such as mothers experiencing postpartum hemorrhage and those develop fistula in the first 24 hours, obstructed labor for new-borns mortality was found to significant risk factors for newborn death in the early three days in Amhara regional state referral hospitals, North-west Ethiopia.

The federal ministry of health of Ethiopia must start the implementation of the WHO recommendation on positive pregnancy experience for addressing the health system and obstetric risk factors of newborn mortality. Further studies focusing on early neonatal death, especially in the first three days, should explore health system factors, maternal factors, and obstetric factors using qualitative data.

\section{Abbreviations}

AHR: Adjusted Hazard Ratio; ANC: Antenatal Care, CHR: Crude Hazard Ratio; Cl: Confidence Interval; ETB: Ethiopian Birr; GA: Gestational Age; SD: Standard Deviation; WHO: World Health Organization

\section{Declarations}

\section{Acknowledgment}

We want to forward our gratitude to Debre Tabor University. We are also grateful to the Amhara regional health bureau and respective referral hospitals. We also would like to thank the data collectors and the study participants.

\section{Authors' contribution}

MD made substantial contributions to, or acquisition of data, drafting the manuscript and revising it critically for relevant intellectual content. AT and SK involved in the conception, design, analysis, and interpretation of data. MD, AT, and SK read and agreed on the final manuscript.

\section{Funding}


Debre Tabor University covered the payment for data collectors and supervisors. However, the University had no role in study design, data collection, and analyses, the decision to publish, and preparing the manuscript.

\section{Availability of data and materials}

The datasets generated during the current study are available from the corresponding author on a reasonable request.

\section{Ethics approval and consent to participate}

Ethical confirmation was granted from the Ethical Review Committee, Debre Tabor University. A formal letter for permission and support was written to the respective administrator office. The aim of the research was undoubtedly clarified to concerned bodies. A permission letter was granted from Amhara regional bureau official and each referral hospital officials. Before informed consent was obtained, the mothers were told that they have the right to be involved or not to be involved in the study. The research aims undoubtedly clarified, informed oral consent-maintained confidentiality ensured, and the process of the study explained to mothers of the neonates. Data collectors read the consent for respondents, and they mark if the respondents agree. Oral permission was obtained because the majority of study subjects cannot read and write to provide them with written informed consent. The study participants were aware that data collectors were skilled only to gather evidence, and the data was not being passed to anybody. The confidentiality of the information (personal identification and idea were not be used in the way which might threaten the respondent) was maintained, and the privacy of the study participants was respected. There was no payment/incentive in participating in this interview.

\section{Consent for publication}

Not applicable.

\section{Competing interests}

The authors declare that they have no competing interests.

\section{Author Details}

${ }^{1}$ Department of Midwifery, Debre Tabor University, Debre Tabor, Ethiopia, ${ }^{2}$ Population and family health, Jimma University, Jimma, Ethiopia, ${ }^{3}$ Department of Midwifery, Bahir Dar University, Bahir Dar, Ethiopia.

\section{References}

1. Hug L, Sharrow D, You D: Levels \& trends in child mortality: report 2017. Estimates developed by the UN Inter-agency Group for Child Mortality Estimation. 2019. 
2. Demographic IE: Health Survey 2016: Key Indicators Report. Addis Ababa, Ethiopia, and Rockville, Maryland, USA. CSA and ICF, 2016.

3. Sankar M, Natarajan C, Das R, Agarwal R, Chandrasekaran A, Paul V: When do newborns die? A systematic review of the timing of overall and cause-specific neonatal deaths in developing countries. Journal of Perinatology 2016, 36(1): S1-S11.

4. Organization WH: Children: reducing mortality. Weekly Epidemiological Record= Relevé épidémiologique hebdomadaire 2014, 89(38):418-420.

5. Shitaye D, Asrat D, Woldeamanuel Y, Worku B: Risk factors and etiology of neonatal sepsis in Tikur Anbessa University Hospital, Ethiopia. Ethiopian medical journal 2010, 48(1):11-21.

6. Tura G, Fantahun M, Worku A: The effect of health facility delivery on neonatal mortality: systematic review and meta-analysis. BMC pregnancy and childbirth 2013, 13(1):1-9.

7. Emiru AA, Alene GD, Debelew GT: Women's retention on the continuum of the maternal care pathway in west Gojjam zone, Ethiopia: a multilevel analysis. BMC Pregnancy and Childbirth 2020, 20:1-14.

8. Oza S, Lawn JE, Hogan DR, Mathers C, Cousens SN: Neonatal cause-of-death estimates for the early and late neonatal periods for 194 countries: 2000-2013. Bulletin of the World Health Organization 2014, 93:19-28.

9. Bayou G, Berhan Y: Perinatal mortality and associated risk factors: a case-control study. Ethiopian journal of health sciences 2012, 22(3).

10. Orsido TT, Asseffa NA, Berheto TM: Predictors of Neonatal mortality in Neonatal intensive care unit at referral Hospital in Southern Ethiopia: a retrospective cohort study. BMC pregnancy and childbirth 2019, 19(1):83.

11. Wakgari N, Wencheko E: Risk factors of neonatal mortality in Ethiopia. Ethiopian Journal of Health Development 2013, 27(3):192-199.

12. Alam N: Teenage motherhood and infant mortality in Bangladesh: maternal age-dependent effect of parity one. Journal of biosocial science 2000, 32(2):229-236.

13. Vogel JP, Souza JP, Mori R, Morisaki N, Lumbiganon P, Laopaiboon M, Ortiz-Panozo E, Hernandez B, Perez-Cuevas R, Roy M et al:: Maternal complications and perinatal mortality: findings of the World Health Organization Multicountry Survey on Maternal and Newborn Health. BJOG 2014, 121 Suppl 1:76-88.

14. Tekelab T, Akibu M, Tagesse N, Tilhaun T, Yohanes Y, Nepal S: Neonatal mortality in Ethiopia: a protocol for systematic review and meta-analysis. Systematic reviews 2019, 8(1):103.

15. Tafere TE, Afework MF, Yalew AW: Does antenatal care service quality influence essential newborn care (ENC) practices? In Bahir Dar City Administration, North West Ethiopia: a prospective follow up study. Italian journal of pediatrics 2018, 44(1):105.

16. Liu L, Oza S, Hogan D, Chu Y, Perin J, Zhu J, Lawn JE, Cousens S, Mathers C, Black RE: Global, regional, and national causes of under-5 mortality in 2000-15: an updated systematic analysis with implications for the Sustainable Development Goals. The Lancet 2016, 388(10063):3027-3035. 
17. Mengesha HG, Sahle BW: Cause of neonatal deaths in Northern Ethiopia: a prospective cohort study. BMC public health, 2017, 17(1):62.

18. Commission CSAoEaAP: Population Projection of Ethiopia for All Regions at WeredaLevel from 2014-2020. Central Statistical Agency of Ethiopia in 2020.

19. Federal Ministry of Health E: Health Sector TransformationPlan 1 Version 1 Annual Performance Report EFY 2008 (2015/16). In: Federal Negarit Gazette. Addis Ababa: Federal Ministry of Health, Ethiopia; 2015.

20. Nakimuli A, Mbalinda SN, Nabirye RC, Kakaire O, Nakubulwa S, Osinde MO, Kakande N, Kaye DK: Stillbirths, neonatal deaths and neonatal near-miss cases attributable to severe obstetric complications: a prospective cohort study in two referral hospitals in Uganda. BMC pediatrics 2015, 15(1):44.

21. Bogale Worku AK, Amha Mekasha, Birkneh Tilahun, Alemayehu Worku: Predictors of early neonatal mortality at a neonatal intensive care unit of a specialized referral teaching hospital in Ethiopia. Ethiop J Health Dev 2012, 26(3):200-207.

22. IGME U: Levels \& Trends in Child Mortality: Report 2017, Estimates Developed by the UN Inter-Agency Group for Child Mortality Estimation. United Nations Children's Fund, New York, 2017.

23. Limaso AA, Dangisso MH, Hibstu DT: Neonatal survival and determinants of mortality in Aroresa district, Southern Ethiopia: a prospective cohort study. BMC pediatrics 2020, 20(1):33.

24. Shifa GT, Ahmed AA, Yalew AW: Early days of life are crucial for child survival in the Gamo Gofa zone, southern Ethiopia: a community-based study. BMC pediatrics 2016, 16(1):30.

25. Desta BN, Assefa N, Damte TD, Hordofa LO: Neonatal mortality and its risk factors in eastern Ethiopia: a prospective cohort study in Kersa health and demographic surveillance system (Kersa HDSS). Mortality, 2016, 13(18):19.

26. Debelew GT, Afework MF, Yalew AW: Determinants and causes of neonatal mortality in Jimma zone, southwest Ethiopia: a multilevel analysis of prospective follow up study. Plos One 2014, 9(9):e107184.

27. Bashir AO, Ibrahim GH, Bashier IA, Adam I: Neonatal mortality in Sudan: analysis of the Sudan household survey, 2010. BMC Public Health, 2013, 13(1):287.

28. Lukonga E, Michelo C: Factors associated with neonatal mortality in the general population: evidence from the 2007 Zambia Demographic and Health Survey (DHS); a cross-sectional study. Pan African Medical Journal, 2015, 20(1).

29. Goba GK, Tsegay H, Gebregergs GB, Mitiku M, Kim KA, Alemayehu M: A facility-based study of factors associated with perinatal mortality in Tigray, northern Ethiopia. Int J Gynaecol Obstet 2018, 141(1):113-119.

30. Tewabe T, Mehariw Y, Negatie E, Yibeltal B: Neonatal mortality in the case of Felege Hiwot referral hospital, Bahir Dar, Amhara Regional State, North West Ethiopia 2016: a one-year retrospective chart review. Ital J Pediatr 2018, 44(1):57. 
31. Imad El Awour YA, Majdi Ashour: Determinants and risk factors of neonatal mortality in the Gaza Strip, occupied Palestinian territory: a case-control study. 2012.

32. WHO: WHO recommendations on Positive pregnancy experience; 2016.

33. Getachew Bayou YB: perinatal mortality and associated risk factors: a case-control study. Ethiop J Health Sci 2012, 22(3).

34. Blandina T Mmbaga RTL, Raimos Olomi1, Michael Johnson Mahande, Oneko Olola1, and Anne Kjersti Daltveit: Causes of perinatal death at a tertiary care hospital in Northern Tanzania 20002010: a registry-based study. BMC Pregnancy Childbirth 2012, 12(139).

35. Getiye Y, Fantahun M: Factors associated with perinatal mortality among public health deliveries in Addis Ababa, Ethiopia, an unmatched case-control study. BMC Pregnancy Childbirth 2017, 17(1):245.

\section{Figures}

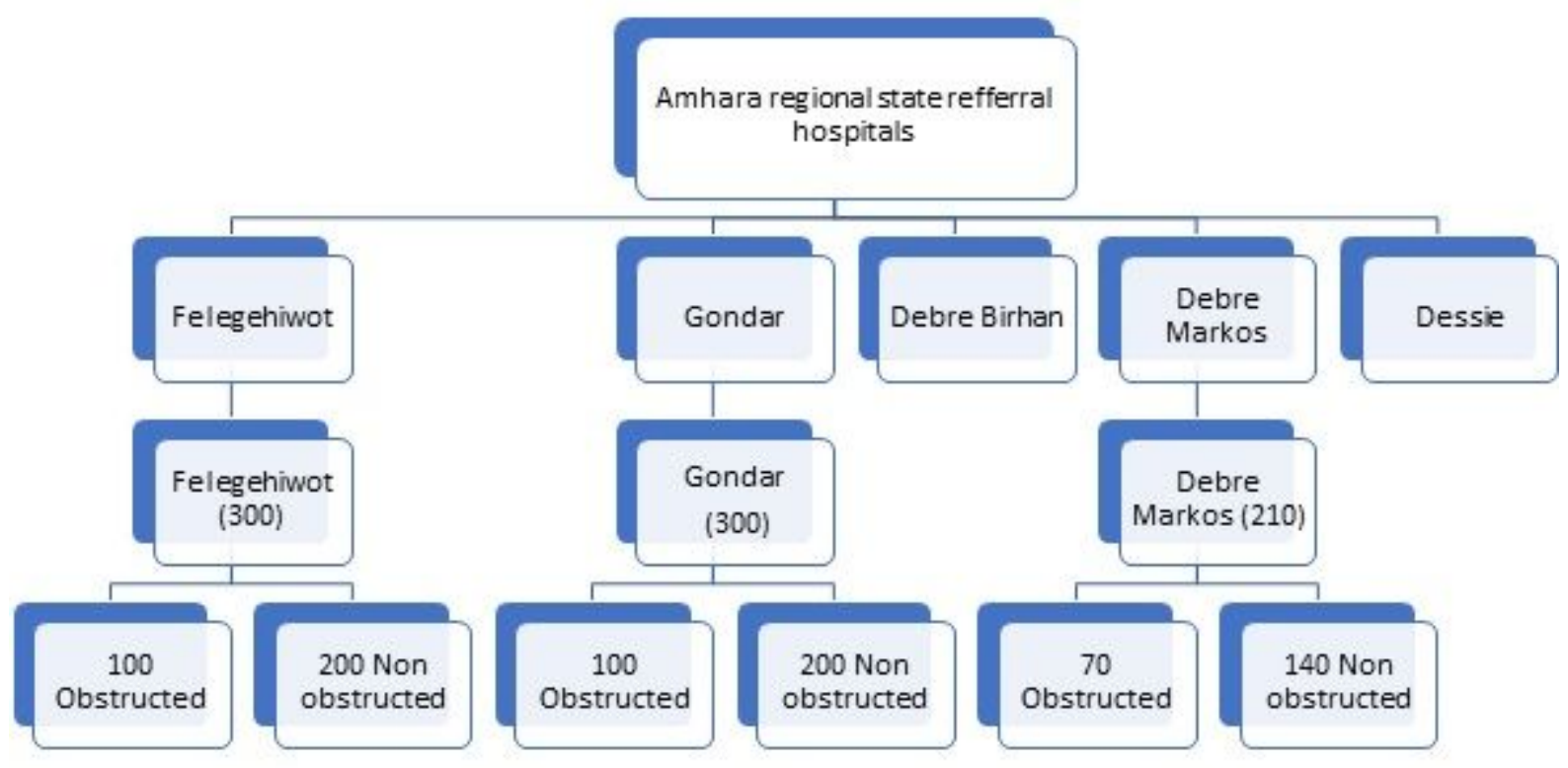

Figure 1

Sample selection procedure. 


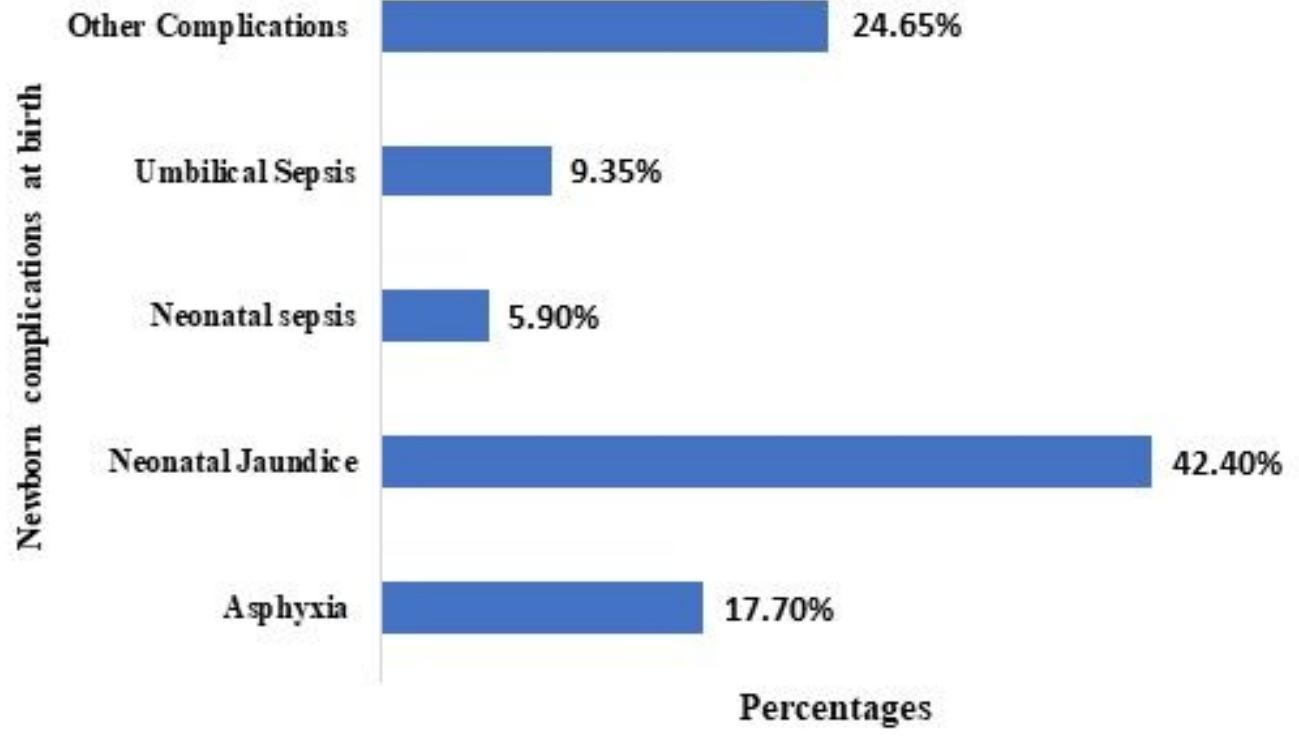

Figure 2

New-borns morbidity in Amhara regional state referral hospitals, Northern Ethiopia, 2018

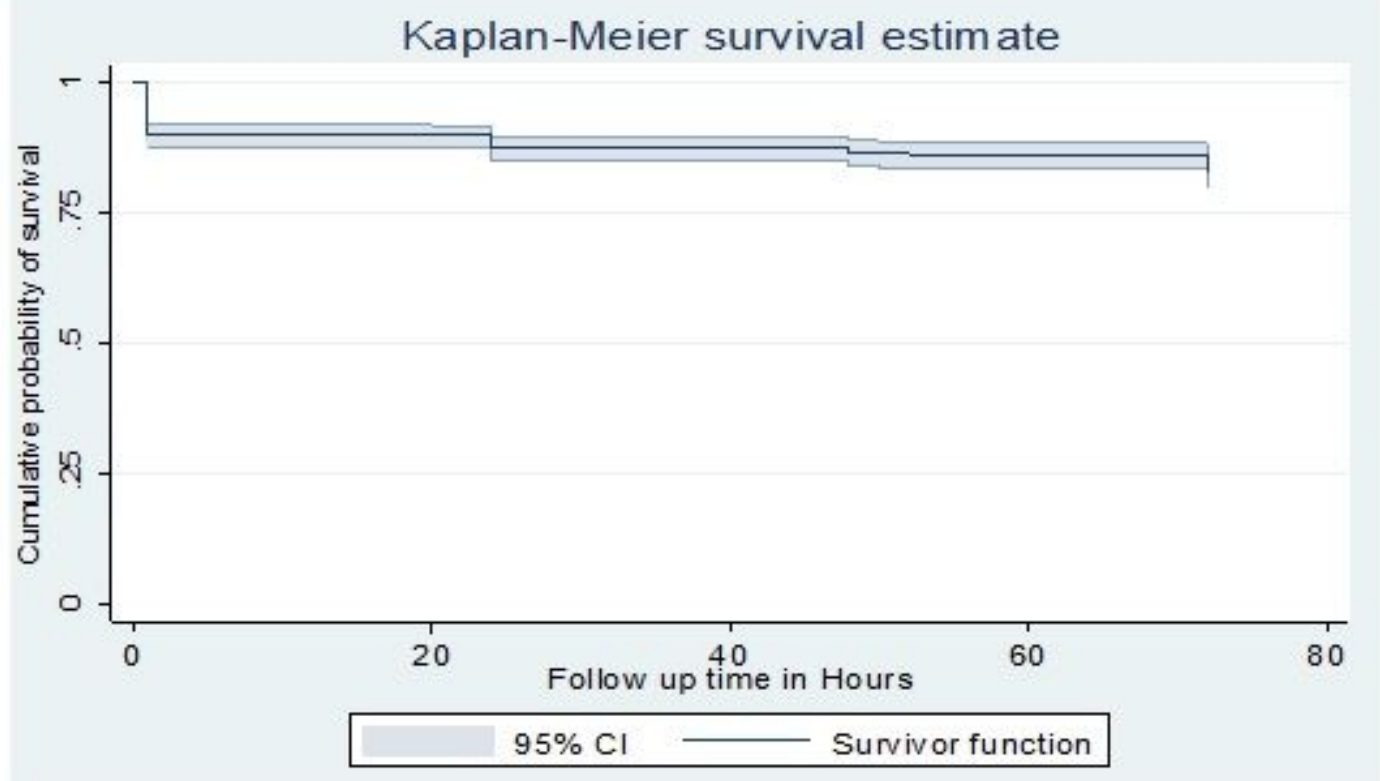

\section{Figure 3}

K-M survival estimate of newborns in Amhara Regional state referral hospitals, Northern Ethiopia, 2018, 


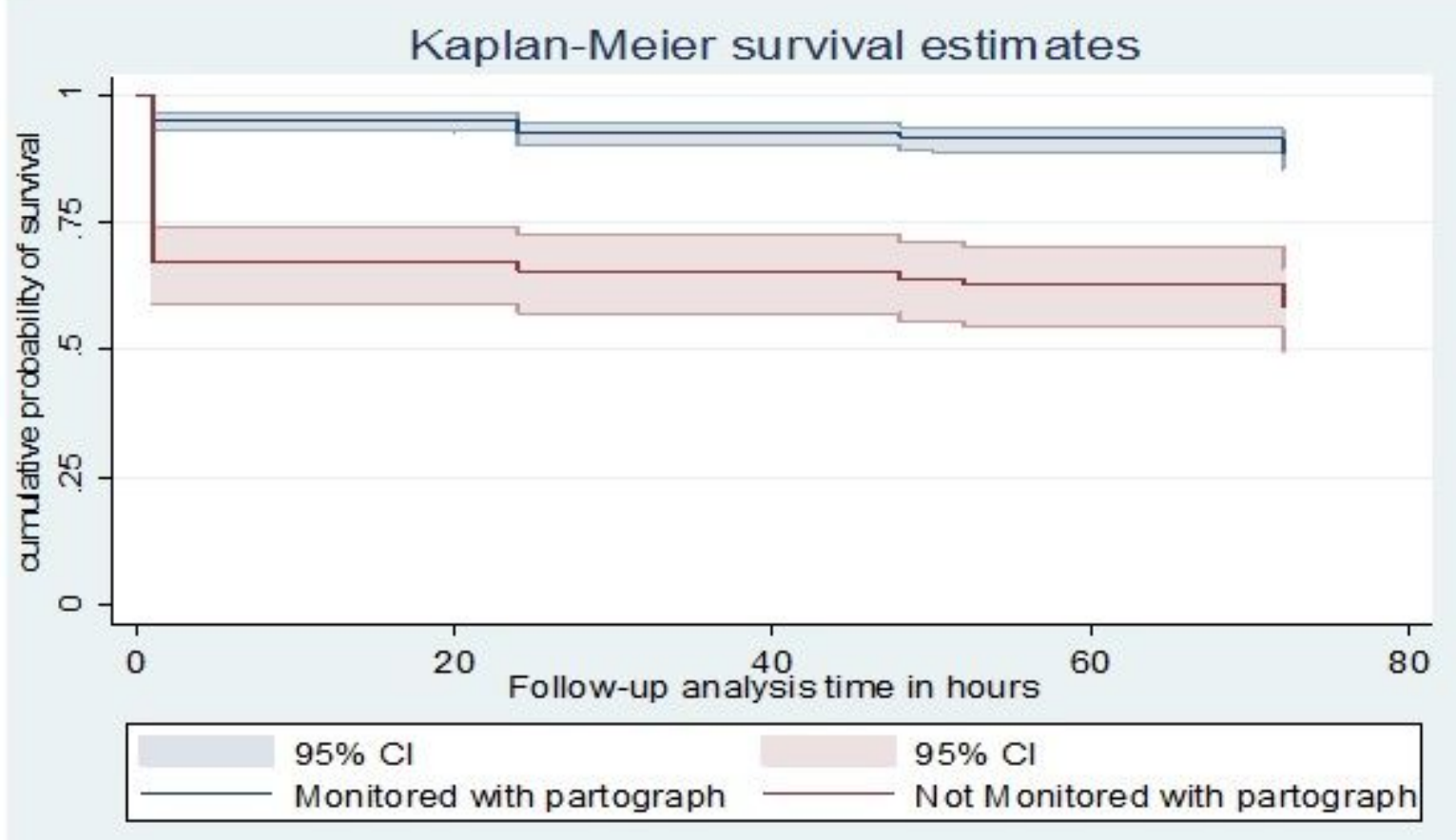

\section{Figure 4}

K-M survival estimate of neonates with labor monitored with partograph Amhara Regional state referral hospitals, North-west Ethiopia, 2018.

\section{Supplementary Files}

This is a list of supplementary files associated with this preprint. Click to download.

- AmharicQuestionniare.docx

- EnglishQustionnaire.docx 